2019-01-18

"A non-person to the rest of the world": experiences of social isolation amongst severely impaired people with multiple sclerosis.

Freeman, Jennifer

http://hdl.handle.net/10026.1/13355

10.1080/09638288.2018.1557267

Disability and Rehabilitation

Taylor \& Francis

All content in PEARL is protected by copyright law. Author manuscripts are made available in accordance with publisher policies. Please cite only the published version using the details provided on the item record or document. In the absence of an open licence (e.g. Creative Commons), permissions for further reuse of content should be sought from the publisher or author. 


\title{
"A non-person to the rest of the world": Experiences of social isolation amongst severely impaired people with Multiple Sclerosis
}

\begin{abstract}
Purpose: To gain insight into the experiences of, and potential solutions to, social isolation amongst severely impaired people with multiple sclerosis.

Methods: A phenomenological research approach using face-to-face, in-depth semistructured, audio-recorded interviews. Data were transcribed and analysed thematically.

Results: Sixteen severely impaired people with multiple sclerosis were interviewed (Expanded Disability Status Scale >6.5); aged 38 to 72 years, nine female, time since diagnosis ranged 4 - 30 years). Four key themes were generated in line with the study objectives, each with further sub-themes. The themes were: 1) Definitions of isolation 2) Causes of isolation 3) lmpact of isolation and 4) Potential eases of isolation.
\end{abstract}

Conclusions: Data portrayed social isolation as complex and multi-factorial in its definitions, its causes, and its impact. Isolation is not just about being lonely or left on one's own, but represents a spiral of impacts. Physical deterioration can lead to reduced choice and control regarding access to, and interaction with others and society, affecting personal identity. Sometimes this leads to further self-isolation. Personalised psychosocial support, with improved ease of access, focused on helping people with severe multiple sclerosis regain a sense of self and their place in the world may ease social isolation.

Key words: multiple sclerosis, social isolation, patient experience 


\section{Introduction}

Multiple sclerosis (MS) affects an estimated 2.3 million people world-wide, and is one of the most common neurodegenerative conditions [1]. Characterised by chronic inflammatory demyelination of the central nervous system, neurological symptoms can involve motor, sensory, visual and cognitive systems. Whilst the clinical presentation and disease course is highly varied and unpredictable, for most people there is a progressive increase in disability over time [2] restricting independence in daily function, employment [3] and social activities [4].

A significant group of people (estimated to be in the region of $20 \%$ ), whose level of mobility is more severely impaired, appear to experience particular restrictions with social participation [4]. Evidence supports that those with greater disability have significantly lower levels of participation in social, home, work and educational domains compared to healthy controls [5]. Moreover, studies provide evidence of moderate to strong correlations between measures of social participation, quality of life [6] and depression [7]. Social participation further plays a vital role in facilitating resilience [8], social adjustment, and living a fulfilled life [9].

The impact of reduced social participation is hypothesized to be social isolation. Defined as the 'objective lack of interactions with others or the wider community'[10, p158], social isolation appears to be more likely experienced by those with greater disability and limited social participation. The functional limitations associated with MS can cause a person to restrict their participation in social activities [6], which may further limit the variety and amount of social interaction [11]. This link is further supported by studies in people with MS, with evidence that people who live with severe MS report feelings of exclusion and isolation as a consequence of their disease [12], and suicidal behaviour [13]. 
Positioning the patient at the heart of care and as the source of control is a fundamental principle of the United Kingdom's National Health Service Constitution [14] and biopsychosocial models of illness and health [15]. When patients with long-term conditions are empowered to manage and control their situation, role in life, and emotional needs, they achieve better outcomes [16]. Whilst there is evidence that the presence of social support contributes to positive health outcomes among this group, more so than illness and demographic factors [17], it is likely that such effects will only occur if the support provided is considered adequate and helpful by the recipient [18]. At face value_MS support groups would appear to be an antidote to social isolation, however experiences have been shown to differ markedly between individuals [9].

There is, however, limited evidence to support 'if', 'how', and 'why' feelings of social isolation develop in people severely impaired by MS and importantly whether or how they may be addressed. Our intention was to use qualitative enquiry to provide insight into this from the perspective of the person severely affected by MS. The specific objectives of the study were to explore: 1) The definition and understanding of isolation; 2) The lived experience of "if" and "how" people are affected by isolation; 3) The reasons why people feel they have become isolated as a result of MS; 4) Whether this isolation could be minimised, and how this might be achieved; 5) The type of support and/or services that could help reduce isolation. We anticipated that greater understanding of the perceived causes of social isolation, its impact and potential eases, would help inform service and support provision for this people with MS. 


\section{Methods}

\section{Research approach and methods}

The paradigm driving the research approach was one of pragmatism, recognising the influence of historical, cultural and political contexts on peoples' experiences [19]. A phenomenological methodology was utilised to examine "the way people interpret and make sense of their experiences and the world in which they live..." [20, p2]. This allowed us to explore the lived experience of people severely impaired with MS, focusing on the anecdotes in the interview transcripts that reflected how people felt their disease affects their sense of place in the world. In-depth, semi-structured interviews allowed for the collection of data where perspectives could be heard within the context of personal history or experience; where delicate or complex issues were able to be explored at a detailed level, and where it was important to relate different issues to individual personal circumstances [21].

An interview schedule was developed in close collaboration with people affected by MS and MS Society Service Development Officers (Table 1). Its intention was to guide the conversation and encourage disclosure and elaboration of thoughts and feelings relevant to the study objectives. It was conducted with sufficient flexibility to enable participants to raise issues they considered important.

Insert table around 1 here

\section{Ethics}

This study was approved by the Northern Ireland Research Ethics Committee (REC Ref: 13/NI/0088) and the Faculty of Health and Human Sciences and Peninsula Medical Schools of Medicine and Dentistry Research Ethics Committee at the University of Plymouth (REC ref: $12 / 13-151)$ 


\section{Sampling and Recruitment}

Purposive sampling to achieve maximum variation according to gender, age and level of disability was used to recruit 16 participants, who perceived themselves to be limited in their access to, and engagement in, activities because of their MS; and who reported that they spent more time alone than they might like, as a result of MS. Recognising that this group is very difficult to reach, a multi-faceted recruitment strategy was used. Firstly, people with MS attending local support groups were asked to give letters of invitation to people they knew who were severely impaired by MS and had limited contact with others. Secondly, an advert was placed in the biannual newsletter of SWIMS (South West Impact of Multiple Sclerosis longitudinal cohort study) [22] which is accessed by approximately 1500 people with MS living in the South West of England. Thirdly, potential participants were sent an invitation letter (together with reply slip and stamped addressed envelope) from the neurology consultant involved in their care, inviting then to participate in the study.

People were eligible to participate if they had a confirmed diagnosis of MS, were restricted to walking short distances with bilateral assistance or reliant upon a wheelchair for mobility (i.e. Expanded Disability Status Scale [EDSS] >6.5), and considered that their impairments limited their access to, and engagement in activities. They were excluded if they could not effectively give informed consent, or had severe communication difficulties that would limit interview.

\section{Data Collection}

Prior to interview, written informed consent was obtained from all participants. Demographic (age, gender) and diagnostic characteristics (MS type, time since diagnosis) were collected by self-report, and cross-referenced with the participants medical records to enable description of the study sample. 
Two pilot interviews were carried out with people with MS to confirm the interview schedule and procedure were appropriate [23]. No changes were required, and subsequently a further 14 face-to-face, semi-structured, audio recorded interviews were conducted by the same interviewer (SR). Interviews were arranged at a time and place considered preferable to the participant. In all cases, this was the home environment. Interviews typically lasted 60 minutes.

\section{Data Analysis}

All interviews were digitally recorded and transcribed verbatim using pseudonymisation in the transcription process. Thematic analysis was performed, using NVIVO 8 software, with inductive coding allowing for the emergence of themes which resonated with the participants' own experiences. Data was interrogated to assess the extent to which there was consistency and divergence in participants' accounts. Emergent individual and common themes were then synthesized.

\section{Ensuring Rigor}

Trustworthiness and credibility of the interpretation of the data were optimized through several strategies. Coding reliability checks were completed (JF and SR) and deemed acceptable [24]. Interview transcriptions and emergent themes were discussed between three authors (SR, HG and JF). Participant validation was undertaken by sending participants a summary of the key topics discussed during the interview. In order to validate the areas covered they were asked to make any responses they wished. Two participants were also asked to read and comment on the draft project report once data analysis was complete.

\section{Reflexivity}

The researchers' personal experience as an anthropologist (SR) and neurological physiotherapists (JF, HG, TG) is recognised as having the potential to influence the research 
process and the manner in which data is interpreted [25]. Therefore, the interviewer (SR) engaged in an ongoing process of reflexivity whereby decisions and actions were recorded and reflected upon in a research diary [26]. Reflection on potential interviewer influence, checking of questions and prompts, and seeing where prompts could have been extended, were discussed, challenged and justified within co-author debriefing sessions (SR, JF).

\section{Study quality}

The COnsolidated criteria for REporting Qualitative research (COREQ) [27] was used to evaluate the reporting of important aspects of the study such as: research team, study methods, context of the study, findings, analysis and interpretations. Each item in the 32-item checklist was met.

\section{Results}

\section{Sample characteristics:}

Seven of the interviewees were male and nine female. Participants experienced different types of MS (relapse remitting and progressive) and varied widely in deterioration rates, with some having lived with a diagnosis for up to 30 years with slow deterioration, and one person diagnosed within the last three years with rapid deterioration. The youngest participant was in her late 30s, the eldest in his 70's (Table 2).

\section{insert table 2 around here}

Four key themes emerged, in line with the study objectives, each with further sub-themes. These were:

1) Definitions of isolation 


\section{2) Causes of isolation}

3) lmpact of isolation, and

4) Potential eases of isolation.

Theme 1: '.....stuck on your own for hours and hours on end.... ': Defining social isolation

Participants' definitions of social isolation were highly expressive and descriptive, demonstrating the impact of isolation through personal experiences of daily life. The definitions reflected subjective experiences and realities, and were very personal in their fields of reference, often picking up on something in particular that had happened. For example, one participant reported that they could no longer access their holiday caravan, which impacted upon social interaction possibilities. Despite the personal nature of the responses, five key sub-themes emerged:

- Being on your own,

- Being cut off/out of reach,

- Finding it difficult to go out/not able to do anything,

- Being reliant on others, and

- Not having the usual interaction with the world.

The five sub-themes describe a spectrum of experiences, which stretches from physical isolation through to limitation on personal interaction.

Isolation being described in terms of "being on your own", is to some extent the most expected idea, as it is when isolation is most closely related to loneliness:

"It's being stuck in your own room you know with your own company. For hours and hours on end". (Male, 41, lives with spouse)) 
Most participants discussed being on their own throughout the day, but for those who live on their own and are reliant on paid carers, the length of time they may be on their own can be extensive:

"They (paid carers) are usually all I see. Four times a day. One day, they couldn't get to me until half past ten in the morning, so that would mean I'd have been in bed for sixteen hours. And as soon as I've had my breakfast it would be quarter to twelve, lunch at half past twelve, tea at four....... And um, then I'm in bed now for thirteen hours and sometimes it just hits you how lonely it can be". (Female, 38, lives alone)

Whilst "being on your own" is about the situation someone is in, "being cut off/out of reach" describes how social isolation is about limitations of interaction with other people. This is more related to the general definition of isolation, which is about separation (for example, “isolating" people when they have a contagious illness). Participants described moving beyond being cut off from people, to being cut off from society and the world. It would appear that being cut off from friends or family through not physically being able to access them, rapidly leads to the sensation of being cut off from the wider world. This in turn impacts on feelings of identity and purpose, with one participant describing feeling ' $a$ nonperson to the rest of the world':

"It's finding that you are probably of your own volition, um, a non-person to the rest of the world. Because you are committed to your own relatively small environment, so most of the world doesn't, because you're not out there and of it, you're... the isolation is actually more of an enclosure. You're not part of that great outside world". (Male, 40, lives with spouse)

Powerlessness to access society is reflected in another sub-theme: "finding it difficult to go out, not being able to do anything" (Jim) due to physical disability. This is isolation in relation to ability, disability and movement. By not being able to move easily and without restriction, participants feel isolated: 
"I suppose I don't really see a lot of people from outside my family... because I find it very difficult going out”. (Female, 68, lives alone)

From this powerlessness due to a lack of physical ability emerges a "reliance on others".

However, reliance on others was described here not simply as an outcome of physical disability, but as a defining feature of social isolation:

"Part of the isolation is the fact that I can't do most of the things that used to make me completely independent". (M, 40, lives with spouse)

Being reliant on others means no longer making their own plans for the day, deciding how to engage socially or reacting spontaneously to situations:

"You've got to rely on other people to take, or when it suits other people to and they are able to take you" (Female, 60, lives with spouse).

As a result of being reliant on others, of being cut off and not being able to do things,

participants identify their social isolation as being because they cannot have the usual social interaction in the world. Their world has changed and they can no longer participate socially in the same way. They can no longer see the same people, go to the same places, have the same daily routines. And to many of the participants, this is the reality of social isolation on a day-to-day level. Social isolation may be about being on your own or being cut-off, but in terms of what it means in practice, it is about a huge change in how people participate in the world, as the following quotes illustrate:

"Not being able to go out and do thing that you want to do, meet the people that you want to, that you used to do. It comes as rather a shock when you can't do any of it". (Female, 38, lives alone)

"I don't know whether it's that you don't involve yourself, but you are not part of it and you don't see people that you used to see". (Female, 53, lives alone)

Theme 2 -'there's so many things you just can't do, you can't do this, you can't do that....':

\section{Causes of social isolation}


The definitions of social isolation offered by the participants point towards multiple causes of social isolation inter-linked in very personal and complex ways. However, despite the complexities in how causes relate to each other and create social isolation, the descriptions given explain isolation in terms of four different factors: Physical separation, social separation, separation from self and separation from agency.

Physical separation connects social isolation to the lack of physical ability to move or function in a way that facilitates daily life. This was the most commonly mentioned cause for social isolation. Examples of these physical restrictions include immobility, incontinence, and fatigue:

“...the adventurous side of my spirit that used to take me out and about and whatever, um, because of various difficulties and physical constraints, have made me isolated in terms of $90 \%$ of what I do is in my own home environment." (Female, 40, lives with spouse)

“.. as the MS got worse.... I couldn't join in because I COULDN'T. I couldn't sort of um, be on equal par to them, because I was sitting here and being in me wheelchair and, um, I felt useless really." (Female, 49, lives alone)

All of the participants used mobility aids of some description, and could not move around their homes or outside of their homes without them. However, most highlighted that whilst these aids (such as electric wheelchairs, motability vehicles and hoists) help increase mobility to a certain extent, they are often very difficult and effortful to use, and generally still require assistance from others. All participants spoke of the complexities of getting out and accessing public spaces, and how those complexities make them reliant on others or on society at large to make it possible for them to get around.

“..actually going out involves, cooperation, getting up, particularly if it's raining and getting up the yard, to get through the garage, to get into the car, which has got a ramp in the back, which means bolting it down which means someone else doing just about everything else". (Male, 40, lives with spouse)

Toileting and incontinence was highlighted by the majority of female participants as being a key issue in keeping them at home, with even short car journeys difficult: 
"I never know whether the incontinence is just going to kick in and er, it can cause such trouble you know... I've got a cover I put over the seats and that, um, but it can be very difficult. This is what holds me back mainly is the incontinence side of things you know". (Female, 68, lives alone)

Fatigue is another physical consideration, with all participants reporting that too much activity makes them tired, and that their day is limited by the need to rest:

"Would I want to do the same things as before? I couldn't. Even if I had that freedom of being able to take myself where I wanted to, I wouldn't do it anymore". (Female, 60, lives with spouse)

Social separation is about separation from society and societal roles whereby social issues cause isolation through people feeling that they cannot act according to the "norms" of social interaction. This leads to feeling "different", to them being unable to make or keep friends, or to make "meaningful contacts". Many participants recounted issues of social embarrassment or shame which cause them to limit their social interactions, particularly around eating, movement and toileting:

"I'm not easily embarrassed, but going, going out, going anywhere to eat out, or to, going out looking tidy, being in amongst people that you don't know, um, because I can't eat properly unless it's finger food and I can pick it up with a bit of luck - so I don't go out much." (Male, 40, lives with spouse)

"It's kind of like sometimes I feel I'm making excuses... so that I don't go out. So I don't get pitied. And so I don't get ignored and I don't get doors slammed in my face, or I don't get somebody saying, you now, can you do this, can you do that?'. (Female, 38, lives alone)

For others, reduced contact with friends was founded by a perceived lack on the friends' part of wanting to engage with them:

“...they just stopped bothering to come and I stopped bothering to phone, because I got the feeling that they didn' $t$ ' want to come. And I also felt like I was nagging, asking them to come. Because it's not as easy, obviously it's not as easy for me to go anywhere and meet them. So I can't meet them for a drink at such and such a place". (Female, 38, lives alone)

Others withdrew as they felt they had nothing interesting to talk about with others: 
"I've got nothing to say, to talk about; there's nothing important in my life that 'ooh about this and that'. I don't do anything because I'm isolated probably but in my mind, so yeah, I feel my life's very boring really, not interesting to other people. I'm not a vitally important person I don't think. It's not a lack of self-confidence, it's not that, it's just that I, what I've got to say wouldn't interest anyone". (Female, 49, lives alone)

As the condition deteriorates or becomes more complex, the individual becomes unable to engage in the activities which gave them purpose and were part of creating their self-identity. For some, this is to do with losing the ability to work, for others it is about not being able to fulfil their role as the cook for the family, or the person who was chair of local community groups. Activities such as these give people a sense of their place in society, in their family and in their relationships, and our participants provided clear stories about how such separation from their own identity, "separation from self", creates social isolation because of the limitations placed on them by their illness.

Separation from self refers to changes in participants' perception of their own identity. Derived from what appears to be a change in life role through losing the ability to work, or fulfilling perceived social or familial roles because of the limitations placed on them by their illness:

"I've spent an awful lot of time just sat doing not much... which after sixty plus years of messing about, um, kind of alienates me....I suppose it's because I've always been able to do all of that, whether it's DIY or work, or making things, whatever, the not being able to do it is of itself isolating". (Male, 72, lives with spouse)

Separation from own agency in the context of social isolation refers to a participant's inability to act, a lack of agency. Participants' described feeling disempowered, relating to lack of independence, choice and control, in the context of their social interactions. For those with more severe disability it could mean no longer having any choice over the timing of their day because of a reliance on paid carers, who work to restricted times. One lady 
described how life is dictated by what others can do for her, including the types of food she eats, who she sees, what she wears and who she talks to. Her days are spent lying in a chair with a television and CCTV so that she can see the outside world:

"I don't move out of this chair until half past seven and, well I see people [through CCTV monitor] going past but I can't say hello to them or anything. A lady across the road, three years ago, when I was out my gardener came and she said "oh it is nice to see you out for a change", and I've never spoken to her since”. (Female, 38, lives alone)

Having limited choice and agency results in some people losing motivation, which in turn increases isolation. One of the participants had made plans to spend some time reading with students in a local primary school, something that she felt to be a positive choice, but it didn't work out:

'I got one of those CRB checks, so that I could go up to the school here and start listening to them reading. But I haven't followed it through. Because if it's raining, I'm not going to go out; and if it's the wrong time of day, I can't go to the toilet. And I can't lift my feet up anymore, and I can't put my shoes on, and it's just like, there's so many things you can't do, you can't do this, you can't do that, so I just watch 'The Wright Stuff' instead' '.' (Female, 53, lives alone)

\section{Theme 3 - '...I do not want another 20 years of this...': Impacts of social isolation}

The key impacts of social isolation, as described by participants, are characterised by their psychological nature. Participants reported being depressed, feeling that they can't be bothered, that they are self-isolating, with some harbouring suicidal thoughts. They either reported directly that they feel very down or depressed, or that they try to keep a happy face on, but 'it's just a face' (Female, 53, lives alone)

“you're a member of a club you don't want to be a member of. It gets you down, you don't want to see people, you, you're therefore more locked inside that mindset". (Male, 50, lives with spouse and children)

For some, the low feelings expressed are suggestive of suicidal feelings:

"You just wonder how long it's going to go on for, because my Mother was 94 when she died. I do not want another 20 years of this. If I died, it wouldn't worry me. It 
would be a relief. "Oh you've got a, you'll be alright, you've got so many more years left in you'. But I don't want so many years LIKE THIS'. (Female, 53, Lives alone)

One participant described putting himself in a position where he almost died, with the knowledge of what he was doing. He was found and resuscitated and was subsequently very angry at being kept alive:

“And it's galling, I've been a physical person all my life, and it's just the last two or three year, as it's got more and more difficult. And the last six months that it's probably accelerated, to the point. And er, it took me to the end. I'm a "happy with euthanasia" person. I don't like not being able to cope for myself. And it's not just about the isolation. Isolation is a big part of it, but you're self-isolating in as much as you're pretty much an object". (Male, 41, lives with spouse)

Isolation, being caused by the difficulties in going out, creates a situation in which people do very little, and this was connected with a lack of motivation to try and do things or make the effort to go out:

"I am not very well motivated. I know there's sometimes when me shopping needs doing and I think I should really go down Tesco's and get some more of that. I think 'aw leave it, I'll go tomorrow'. I put off going out. I've not got agoraphobia, it's not that. It's not that I'm frightened to go out, I don't, I can't be bothered to go out'. (Female, 49, lives alone)

This lack of motivation, the feeling of "can't be bothered", appeared to be accompanied by feelings of uselessness:

"I could have been doing something but I don't know what I could be doing. Cos I'm not fit to do anything. I can't, achieve anything cos I, I can't do anything. I mean I physically can't do anything, so I can't think what else I could achieve”. (Female, 49, lives alone)

Further psychological impacts appear to occur when people feel that the isolation is of their own doing, which many participants did. The use of the term "self-isolation" was common. When people felt that social contact or interaction is complicated and not working, when they feel different and disengaged, they report that they choose to withdraw and make a conscious decision not to engage: 
"Any way you look at it, it's a self-isolation. There is no requirement that I should be isolated. It's just the effort required to do anything outside, has become more and more difficult, and I am more and more reliant on someone else doing it all". (Male, 40, lives with spouse)

\section{Theme 4 - '...I don't even have a vision': Potential eases of social isolation}

Many participants found it extremely difficult to see ways that could help reduce social isolation.

'I literally don't have an answer. I just feel completely and utterly pushed in a corner where there is not a sensible outcome'... 'It's hopeless isn't it? I don't know. I don't even have a vision". (Male, 50, lives with spouse and children)

There were, however, some positive comments from participants. The experiences of those who reported very low social isolation, in spite of severe disability, may provide insight into how isolation may be avoided or reduced:

"I've got a vehicle that my wheelchair fits in the back of, so that I can travel around the countryside. I've got friends that I go out nearly every weekend with; for a meal.... I go to the cinema, I go to shows you know.... People have seen me get, seen me get worse, you know, but they've stuck with it ... and I can still talk the hind legs off a donkey. I think that must be terrible for people who can't talk". (Male, 41, lives with spouse)

Some of these participants had a level of resilience to their situations that did not appear to be purely to do with the input of friends and family, use of technology or adaptations. They appeared to be particularly adept at positive adaptation to their situation in a way that was not the case for everyone. For example, for some participants, physical disability and subsequent inability to get out was viewed positively:

"It means I've more time to do the things I didn't have time to do before, like keep in more contact with friends and family through Skype...". (Female, 60, lives with spouse)

This group demonstrated a particular mind-set which focused on positivity in relation to their situation: 
"I made the conscious decision three or four years ago, that, that you could sink or swim. And I decided to swim. So, um, so with what I've got left, I mean I think talking to one or two other MS, people with MS, well I certainly use that word - that it steals from you, you know. It steals various abilities but I've still got some of them. So I still use the ones I've got'. (Female, 60, lives with spouse)

MS support services seem the obvious place for support and to ease feelings of social isolation. It was therefore important to understand how people used, viewed and related to the different services (statutory and non-statutory) available to them. For the majority of participants, MS group-based initiatives were not viewed positively. Reports of having nothing in common with the people at the support meetings other than their illness were common:

"I don't want to be surrounded by people that have got MS". (Female, 53, lives alone)

Underlying reasons included: not wanting to hear about the problems of other people with MS, how things can be worse, and not wanting to hear positive things when feeling negative.

However, not all dismissed group support. Two participants felt groups provide an important interaction with others who understand their situation, and help them come to terms with their MS:

"... they're (members at the MS group) the only ones that really understand what you're going through, when you say I've got a certain problem”. (Male, 51, lives with spouse)

Those who have accessed support at specialist MS centres $(n=4)$ spoke very highly of their experiences. However, in rural areas accessing such centres is dependent on transport availability, carer support or formal services, with three of the four people having to stop using the services because of logistical issues:

"We used to go there but it's so far to go to. .. by the time I'd come home I'm absolutely shattered. So whatever good they did there by the time I got back it was all a waste of time". (Female, 58, lives with spouse) 
Two people reported accessing direct payments (initiatives designed to enable the person with MS and their carer to make individually relevant choices about the care and lifestyle they need). Such payments, for example, enabled one participant to pay for herself and her husband to go out for dinner so that her husband has time off from the cooking, and they can do something "normal" together.

Whilst some did access such payments and associated packages of care, many found the complexities of the system frustrating:

"..there seem to be so many aspects of it. But you don't realise and you say can you speak to so and so and "no, they're not in today", you know and "she'll ring you when they're next in." And that's probably three weeks later". (Female, 62, lives with spouse)

Others commented that MS symptoms severely hampered their ability to process the complexity of accessing help:

"My brain's not working as fast as it was, and I think I can't handle all this, so I shut off". (Female, 49, lives alone)

Volitional reluctance to contact services with a view to easing social isolation was also identified. This appeared to be driven by perceptions of the services being too busy, or by the feeling that they didn't expect to get support, especially not in relation to easing social isolation:

“They're very busy. I wouldn't expect them to". (Female, 38, lives alone)

"Too much is put on the health services I think". (Male, 51, lives with spouse) In several cases, support was received only once a crisis had occurred. For example, after struggling to cope for a number of years, one couple finally received emergency input from social services after the husband reported both his wife and himself to be suicidal due to how difficult and isolated their lives had become:

"Yeah, you just see nobody tells you what help is out there and if you don't ask. As I say this time last year, we were, both of us were sinking fast... We were both, we'd had 
enough, we were both suicidal. Um, and give them there due when we did shout, they were here, you know we had a phone call in the morning, and the lady from social services said well how urgently do I need to put this referral down as. And my voice started trembling as I was talking to her, because I was so, um, and she said oh, I'll put it down as vey urgent...". (Female, 57, lives with spouse)

Family and spousal carers play an essential role in reducing feelings of isolation in the person with MS. All of those who were supported by their spouse spoke vividly of how carer input enabled them to interact with the world. However, the intensity, complexity and fragility of the carer relationship was also reported by many, with carers often giving up work to take on the caring role. As one participant said, "we had to get used to living together" (Female, 62, lives with spouse). This is another area where life roles and identity changes as the person with MS becomes cared for by their spouse, and less able to provide care and support themselves. Their "previous" life as a couple changes from being two independent beings who have their own activities, jobs, interests and so on, to being two people who have to spend most of their time together. Participants voiced the pressure this can place on relationships:

“(partner) does his absolute utmost to take me out and we go places. Urm, but it's very much just the two of us and it puts a huge amount of pressure on our relationship, the isolation because I, well I don't see anyone really, we don't have anyone to talk to except each other. Which can be hard work really. Even after thirty years of being together it's, it's hard work". (Female, 57, lives with spouse)

Given the reliance on the carer, deterioration in the health and wellbeing of the carer was commonly reported, particularly in the older carers, with the inevitable impact on the ability to get out and social isolation:

"My wife used to be able to get me to the car and so on. But now she's got to the point, she's dislocated her hip now four times this year; which is not very good and er, she can't push to get me in the car... so you can't get out". (Male, 72, lives with spouse) 


\section{Discussion}

This study provides unique insight into the experience of social isolation from the perspective of severely impaired people with MS. Our study participants highlighted that whilst social isolation may start with physical restrictions, it develops and is perpetuated through social experiences and the emotional/psychological responses to those restrictions. Study participants described social isolation in the context of choice and control; not able to choose what they do unless someone is there to support them. This in turn changed their interaction with others and their perception of how others viewed them, expressing this in terms of feeling like a burden. Embedded within this, social isolation affected their relationship with others, and resulted in the perception that they no longer had a place in the world, in their family or community. In essence many participants reported no longer having a purpose in life, and felt either powerless or unmotivated to address this. Subsequent feelings of guilt and worthlessness increased feelings of being a burden which led to a cascade of impacts into social isolation.

There are several limitations to this study. First, the participants' willingness to provide information that would satisfy the interviewer, who was an anthropologist, may have led to potentially exaggerated and/or inaccurate descriptions. Whilst most participants were informed of the professional background of the interviewer, it was emphasised at the beginning of the interview that responses would be anonymous and would not affect any current or future clinical care. Second, the majority of interviews were conducted with people with MS who were several years post diagnosis, so recall of interventions and experiences may have been variable. Third, this study purposively recruited adults who were severely impaired and therefore reflects the experiences of those with this level of disability rather than the wider MS population. 
Four themes emerged from this study, describing how people with MS define social isolation, what causes it, how it impacts on them, and how they feel it might be eased. The data portrays social isolation as complex and multi-factorial. It represents a personal spiral, or cascade of impacts, inter-linked by a perceived lack of choice and control over the situation. Potential solutions to ease isolation were difficult to envisage by those experiencing isolation, hampered by feeling 'cornered', 'powerless', 'poorly motivated', and that isolation was often 'self-imposed'. The diverse experiences described, however, indicate that isolation is not an inevitable consequence of deteriorating physical ability, suggesting it is amenable to change. Identifying personal perceptions and individual needs in order to optimize the psychosocial support provided by health and social care professionals and third sector organisations is emphasised by the findings of this study.

The feelings expressed by participants which run through each theme, relate to a sense of powerlessness, lack of choice or control. Many participants used these terms to define social isolation, to highlight the causes of their social isolation, how it impacts on them and, ultimately, what they saw as potential solutions. This study raises an important issue: people severely impaired by MS do not always feel in control of either preventing their situation, managing it, or getting out of it. Approaches which promote self-management are strongly associated with perceived control, which can mediate the relationships between the physical and emotional impact of MS and quality of life [28]. Although effective self-management strategies have yet to be fully established in MS [29], the use of online, telehealth and telephone support groups may provide one such approach in this hard to reach population. These approaches negate the need to travel and may address several aspects of isolation highlighted by participants in this study. Importantly, studies have demonstrated that it is feasible for people with MS to engage in programmes delivered using these types of media [30-32]. 
Causes of isolation were expressed by many in the context of reduced social participation, in line with previous studies [4-6]. This study is unique, however, in that participants describe a cascade of impacts leading to social isolation. Limited physical ability, leads to reduced social participation as result of issues with continence, toileting, access, eating and reliance on others. These difficulties trigger feelings of shame and embarrassment and, faced with an inability to interact on one's own terms, and with ease, lead to feelings of worthlessness, depression and in some, suicidal behaviour. High levels of depression [33] and increased risk of suicidal behaviour [15] in people with MS are reported, supporting our findings and emphasising the need for psychological support for this patient population.

That many participants report further isolation through "self-imposed isolation" is also a key finding of this study. Choosing to withdraw from social interaction altogether would appear to further contribute to poorer health outcomes, as socially isolated individuals may suffer more stress than others due to their lack of social networks and support, and when they do, are more likely to withdraw into themselves [34].Critical was how most of these severely impaired participants expressed having lost their sense of self, purpose or place in life. The limited ability to act according to their own will, having to rely on others, resulted in feeling unable to fulfil previously held societal or familial roles. This study highlights the importance of helping people with MS find meaning, a role, a purpose in life. The maintenance of preexisting social roles and relationships is vital as others have described how they provide a meaningful basis for integrating the old with new senses of self [9].

MS support groups, whilst an obvious solution to ease isolation, were viewed unfavourably by most study participants. Many felt their experiences of MS were not comparable to those of others, or did not like to see people in a 'worse state' than themselves. Some, however, did find MS support groups useful, particularly in coming to terms with the changes that MS imposed. The reluctance to engage with MS-specific groups also relates to control and 
choice; participants felt they were obliged to relate to people because they had MS, even if they had nothing else in common. Having a "normal" friendship or social interaction around an interest rather than an illness was very hard for many participants. Others [35] have described similar situations in which people do not want to be defined by their MS, and so potential group solutions must look beyond the diagnosis, such as focusing on personal interests or hobbies. Conflicting support for MS groups have been reported elsewhere [9] suggesting MS support groups should not automatically be seen as the obvious antidote to social isolation.

Our study highlights that social isolation is influenced by personal, emotional and psychological responses to physical disability. Whilst a worsening of disease symptoms triggered social isolation for some, not all participants with severe impairment felt markedly isolated. For some it was a mind-set: 'not minding so much' or viewing and using the isolation for more productive endeavours. These findings support the notion that some participants had greater resilience, defined as the capacity to persist, bounce back and flourish when faced with stressors [36]. Resilience, which is positively associated with satisfaction with social roles and quality of life in those with physical disabilities [37], is now considered a modifiable construct, and demonstrated to be amenable to intervention [38]. The findings from a recent qualitative study identified several barriers and facilitators to resilience, many of which have social drivers, further emphasising the link between social isolation and resilience [8] and the suggestion that resilience may be a key factor to reducing feelings of socially isolation.

This study adds further support that the needs of people with severe MS transcend purely biomedical issues and embrace psychosocial aspects. Health and social care services for people with MS need to provide greater focus on promoting such support, enabling people with MS to feel normal, regain a sense of control, and feel a valued part of society. 
Government policies [39], the biopsychosocial model of care [15] and research in this area place value on providing accessible and implementable psychosocial support. The challenge is to encourage debate on difficult topics such as social isolation, so that training initiatives may be targeted at those who are able and willing to address these issues with patients. Moreover, psychosocial support may mediate responses to other areas of rehabilitation by facilitating motivation, optimism, clearer goals, and consequently resilience [40].

What must also be considered, where pre-existing services exist, is the ease of accessing services. In line with other studies $[41,42]$ for many participants the sequelae of MS made it difficult to navigate the complexities of accessing care and support; for others it was feeling their needs were not important enough to be addressed by an already overstretched service. The net result was that support services were not utilised. Mechanisms such as a keyworker/ co-ordinator, simplifying access pathways and providing information about the importance of psychosocial welfare in people severely impaired by MS and their carers, may help to address these issues [43].

\section{Conclusion}

Our findings point toward personalised psychosocial care as being important for people severely impaired by MS who experience severe social isolation. For some, this might involve helping them to engage in old hobbies, or with members of their family through the use of online communication technology such as skype, or adapted aids. For others, this might mean identifying new activities or groups to engage with and finding ways for that to happen. Above all, people severely impaired by MS need to feel that they are not a burden, that they can make decisions, that their actions have meaning and that they have a place in the world and a reason for interacting. To reduce experiences of social isolation, it is not enough 
to just increase social contact; people also need to be helped to identify their role in their world and helped to find a sense of purpose.

\section{References}

1. Browne P, Chandraratna D, Angood C et al. Atlas of Multiple Sclerosis 2013: A growing global problem with widespread inequity. Neurology 2014; 83(11): 10221024

2. Feinstein A, Freeman J, Lo AC. Treatment of progressive multiple sclerosis: what works, what does not, and what is needed. Lancet Neurol. 2015;14(2):194-207

3. Bøe Lunde HM, Telstad W, Grytten N, Kyte L, Aarseth J, Myhr K-M, et al. (2014) Employment among Patients with Multiple Sclerosis-A Population Study. PLoS ONE 9(7): e103317.

4. Kierkegaard M, Einarsson U, Gottberg K, von Koch L, Holmqvist LW: The relationship between walking, manual dexterity, cognition and activity/participation in persons with multiple sclerosis. Mult Scler 2012, 18:639-646

5. Cattaneo D, Lamers D, Bertoni R, et al. Participation Restriction in People With Multiple Sclerosis: Prevalence and Correlations With Cognitive, Walking, Balance, and Upper Limb Impairments. Archives of Physical Medicine and Rehabilitation 2017;98 (7): 1308-1315

6. Kwiatkowski A, Marissal J-P, Pouyfaucon M, Vermersch P, Hautecoeur P, Dervaux B. Social participation in patients with multiple sclerosis: correlations between disability and economic burden. BMC Neurology. 2014;14:115-.

7. Kirchner T, Lara S. Stress and depression symptoms in patients with multiple sclerosis: the mediating role of the loss of social functioning. Acta Neurol Scand: 2011: 123: 407-413

8. Silverman AM, Verrall AM, Alschuler KN, Smith AE, Ehde DM. Bouncing back again, and again: a qualitative study of resilience in people with multiple sclerosis. Disability and Rehabilitation. 2017;39(1):14-22.

9. Tabuteau-Harrison S, Haslam C \& Mewse A. Adjusting to living with multiple sclerosis: The role of social groups. Neuropsychological Rehabilitation, 2016;26:1, 36-59

10. Leigh-Hunt N, Bagguley D, Bash K, et al. An overview of systematic reviews on the public health consequences of social isolation and loneliness. Public Health. 2017 Nov;152:157-171.

11. Dennison L, Yardley L, Devereux A, Moss-Morris R. Experiences of adjusting to early stage Multiple Sclerosis. J Health Psychol. 2011; 6(3):478-88. 
12. Feinstein A. An examination of suicidal intent in patients with multiple sclerosis. Neurology. 2002 Sep 10;59(5):674-8.

13. Pompili M, Forte A, Palermo $\mathrm{M}$ et al. Suicide risk in multiple sclerosis: A systematic review of current literature. Journal of Psychosomatic Research 2012; 73(6):411-417

14. Department of Health (2015) The NHS Constitution: the NHS belongs to us all. DoH

15. Wade D \& Halligan P. The biopsychosocial model of illness: a model whose time has come. Clin Rehabil 2017; 31(8) 995-1004

16. Small N, Bower P, Chew-Graham CA, Whalley D, Protheroe J. Patient empowerment in long-term conditions: development and preliminary testing of a new measure. $B M C$ Health Serv Res. 2013;13:263.

17. McCabe M \& O'Connor E. Why are some people with neurological illness more resilient than others? Psychol Health Med 2012; 17(1):17-34

18. Rommer P, Sühnel A, König N, Zettl U. Coping with multiple sclerosis-the role of social support. Acta Neurol Scand. 2017; 136(1):11-16

19. Morgan DL. Pragmatism as a Paradigm for Social Research. Qualitative Inquiry 2014;20(8):1045-53.

20. Holloway I. (1997) Basic concepts for Qualitative Research. Oxford. Blackwell Science.

21. Ritchie and Lewis (2003) Qualitative Research Practice: A guide for social science students and researchers. Sage Publications. London

22. Zajicek JP, Ingram WM, Vickery J, Creanor S, Wright DE, Hobart JC. Patientorientated longitudinal study of multiple sclerosis in south west England (The South West Impact of Multiple Sclerosis Project, SWIMS) 1: protocol and baseline characteristics of cohort. BMC Neurology. 2010;10:88.

23. Paterson B, Scott-Findlay S. Critical issues in interviewing people with traumatic brain injury. Qual Health Res 2002;12: 399-409.

24. Miles M, Huberman A. Early steps in analysis. An expanded sourcebook: qualitative data analysis. 2nd ed. London: Sage Publications; 1994.

25. Carpenter C, Suto M. Qualitative Research for Occupational Therapists and Physical Therapists: A Practical Guide. Oxford: Blackwell Publishing, 2008

26. Haynes K. Reflexivity in qualitative research. In: Symon G, Cassell C, editors. Qualitative organizational research : core methods and current challenges. London: SAGE; 2012. page 72-89.

27. Tong A, Sainsbury P, Craig J. Consolidated criteria for reporting qualitative research (COREQ): a. 32-item checklist for interviews and focus groups. International Journal for Quality in Health Care. 2007; 19 (6): 349 - 357 
28. Bishop M, Frain MP, Tschopp MK. Self-management, perceived control, and subjective quality of life in multiple sclerosis: an exploratory study. Rehabil Couns Bull. 2008;52:45-56.

29. Fraser, R, Ehde D, Amtmann D, Verrall A Johnson K, et al. Self-Management for People with Multiple Sclerosis: Report from the First International Consensus Conference, November 15, 2010. Int J MS Care. 2013;15:99-106.

30. Cecil A. An 8-Year Telephone Support Group for Home Bound People with Multiple Sclerosis: Adapting Therapeutic Methods to Overcome Isolation and Immobility. Social Work With Groups 2014;37:2, 129-141

31. Bombardier CH, Cunniffe M, Wadhwani R, Gibbons LE, Blake KD, Kraft GH. The efficacy of telephone counseling for health promotion in people with multiple sclerosis: a randomized controlled trial. Arch Phys Med Rehabil. 2008;89:1849-1856

32. Finlayson M, Preissner K, Cho C, Plow M. Randomized trial of a teleconferencedelivered fatigue management program for people with multiple sclerosis. Mult Scler. 2011;17:1130-1140

33. Boeschoten RE, Braamse AMJ, Beekman ATF, Cuijpers P, van Oppen P, Dekker J, et al. Prevalence of depression and anxiety in Multiple Sclerosis: A systematic review and meta-analysis. Journal of the Neurological Sciences. 2017;372:331-41.

34. Cacioppo JT, Hawkley LC. Social isolation and health, with an emphasis on underlying mechanisms. Perspect Biol Med 2003;46:S39-52

35. Grose J, Freeman J, Skirton, H. Value of a confidant relationship in psychosocial care of people with multiple sclerosis. Int J MS Care 2012;14:115-22

36. Bonanno GA. Loss, trauma, and human resilience: have we underestimated the human capacity to thrive after extremely aversive events? Am Psychol. 2004;59: 20-28.

37. Battalio SL, Silverman AM, Ehde DM, Amtmann D, Edwards KA, Jensen MP. Resilience and Function in Adults With Physical Disabilities: An Observational Study Arch Phys Med Rehabil. 2017 Jun;98(6):1158-1164.

38. Pakenham KI, Mawdsley M, Brown FL, Burton NW. Pilot Evaluation of a Resilience Training Program for People With Multiple Sclerosis. Rehabil Psychol. 2018 Feb;63(1):29-42.

39. Department of Health (2011) White Paper: Healthy Lives, Healthy People: our strategy for public health in England. HMSO

40. Lee J, Ready E, Davis E \& Doyle P. Purposefulness as a critical factor in functioning, disability and health. Clinical Rehabilitation 2017; 31(8) 1005-1018

41. Methley AM, Chew-Graham C, Campbell S, Cheraghi-Sohi S. Experiences of UK health-care services for people with Multiple Sclerosis: a systematic narrative review. Health Expectations. 2015;18(6):1844-55. 
42. Chiu C, Bishop M, Pionke JJ, Strauser D, Santens RL. Barriers to the Accessibility and Continuity of Health-Care Services in People with Multiple Sclerosis.

International Journal of MS Care. 2017;19(6):313-21

43. Haas BM, Price L, Freeman JA. Qualitative evaluation of a Community Peer Support Service for people with spinal cord injury. Spinal cord. 2012;51:295. 
Tables

Table 1. Interview Schedule

What is your understanding of the term isolation?

Do you feel you are isolated?

How did this happen?

How has this impacted you?

How do you feel about this?

When did these feelings of isolation start?

Is there anything at all at the moment that helps to ease your sense of isolation?

Have you done anything before/ in the past to try to ease your isolation? Did it/ how did it help? / If stopped then why did you stop doing it?

In an ideal world what would you like to do (to be able to do) to ease this?

What could help you to do this, how would this work best for you?

Are there any ways that you feel health services could ease your feelings of isolation?

What other ideas and suggestions could you make?

Is there anything you would like to say that you don't feel you have had the chance to in this interview? 
Table 2. Participant demographic, clinical and social characteristics

\begin{tabular}{|c|c|c|c|c|c|}
\hline Participant & Gender & $\begin{array}{c}\text { Age } \\
\text { (years) }\end{array}$ & $\begin{array}{c}\text { Time since } \\
\text { diagnosis } \\
\text { (years) }\end{array}$ & MS Type & Social situation \\
\hline 1 & Male & 40 & 4 & RR & Lives with spouse \\
\hline 2 & Female & 53 & 8 & PP & Lives alone \\
\hline 3 & Female & 60 & 30 & SP & Lives with spouse \\
\hline 4 & Male & 50 & 8 & SP & Lives with spouse and children \\
\hline 5 & Female & 38 & 12 & SP & Lives alone \\
\hline 6 & Male & 51 & 9 & SP & $\begin{array}{l}\text { Lives with spouse; children } \\
\text { nearby }\end{array}$ \\
\hline 7 & Male & 41 & 6 & $\mathrm{RR}$ & Lives with spouse \\
\hline 8 & Female & 62 & 22 & $\mathrm{RR}$ & Lives with spouse \\
\hline 9 & Female & 49 & 8 & $\mathrm{RR}$ & Lives alone \\
\hline 10 & Female & 68 & 19 & SP & Live alone; daughter next door \\
\hline 11 & Female & 57 & 7 & SP & Lives with disabled spouse \\
\hline 12 & Male & 63 & 3 & PP & Lives with spouse \\
\hline 13 & Male & 66 & 22 & SP & Lives with spouse \\
\hline 14 & Male & 72 & 17 & SP & Lives with spouse \\
\hline 15 & Female & 58 & 13 & $\mathrm{RR}$ & Lives with spouse \\
\hline 16 & Female & 51 & 22 & $\mathrm{RR}$ & Lives with spouse \\
\hline
\end{tabular}

Abbreviations: RR, relapse-remitting; PP, primary progressive; SP, secondary progressive 